\title{
Challenges in pulmonary fibrosis: 8 - The need for an international registry for idiopathic pulmonary fibrosis
}

\author{
J W Wilson, ${ }^{1}$ R M du Bois, ${ }^{2}$ T E King Jr ${ }^{3}$
}

${ }^{1}$ Department of Allergy, Immunology and Respiratory Medicine, Alfred Hospital and Monash University, Melbourne, Australia; ${ }^{2}$ Royal Brompton Hospital, London SW3 6NP, UK:

${ }^{3}$ San Francisco General

Hospital, San Francisco,

California, USA

Correspondence to: Dr J Wilson, Department of Allergy, Immunology and

Respiratory Medicine, Alfred Hospital and Monash University, Commercial Road, Melbourne 3004, Australia; john.wilson@ med.monash.edu.au

Received 10 February 2006 Accepted 6 July 2006

\begin{abstract}
Improved survival from idiopathic pulmonary fibrosis (IPF) is dependent on better understanding of the epidemiology of the disease, its diagnostic spectrum in global terms and an analysis of outcomes from emerging therapies at a significant level. Outside major lung transplant centres, few institutions have significant numbers to provide this information. Relevant examples exist to justify the establishment of registry data to achieve these aims. The gains seen in cystic fibrosis, lymphangioleiomyomatosis and lung transplantation over the past decade stem from optimisation of treatment plans through registry data. We advocate for an international registry to achieve better outcomes in IPF.
\end{abstract}

Globally, there are significant differences in the incidence, prevalence, diagnostic approach, therapies and survival for patients with idiopathic pulmonary fibrosis (IPF). For example, the prevalence of IPF varies widely depending on location, identifying criteria and year of study, ranging from 3-6 per 100000 in the UK up to 16-18 per 100000 in Finland. ${ }^{1}$ It is not known if these differences are real or the result of differing methods of identifying, classifying or confirming the diagnosis.

Recently, increasing use of the approaches to diagnosis and classification of IPF outlined in two American Thoracic Society (ATS) and European Respiratory (ERS) consensus statements has led to greater uniformity in case identification worldwide. $^{2}{ }^{3}$ Importantly, use of these criteria has supported the development of international clinical trials of treatment. Unfortunately, because of the low incidence and prevalence of IPF, collection of reliable and meaningful data requires multicentre participation. Furthermore, useful deductions regarding treatment and outcomes are limited by lack of power. Consequently, we renew the call for the development of an international registry for patients with IPF.

\section{DEMONSTRATED VALUE OF OTHER LUNG DISEASE REGISTRIES}

Analogies drawn from useful well-structured databases of lung disease have been most valuable in identifying co-morbidities and providing evidence to support advances in care. For example, in systemic sclerosis, database analysis clearly identified the role of pulmonary hypertension in contributing to mortality. ${ }^{4}$ Indeed, the recognition of pulmonary hypertension in patients on a lung transplant registry has identified a significant adverse factor for outcome in patients with IPF undergoing assessment for this procedure. ${ }^{5}$ The UNOS/ISHALT international registry for organ transplantation has been most useful for identifying trends in referral, outcomes for specific indications and for highlighting clinically important comorbidities. ${ }^{6-8}$ Further valuable information can be derived from lung transplantation databases of relevance to IPF, particularly in relation to access to procedure, the relative survival benefit derived ${ }^{9}$ and the likelihood of achieving transplantation in relation to other lung diseases. ${ }^{10}$ Until recently, the only factor that affected a patient's ranking on the transplant waiting list for lungs was the length of time on the waiting list and the location of the transplant centre in relation to the donor. However, after evaluation of registry data and learning that most patients with IPF die before receiving their transplant at a much higher rate than other patients, this is the only group of patients that are afforded any priority. Therefore, a patient with IPF who is listed may automatically be credited with 90 days of waiting list time.

The recent development of a registry for patients with lymphangioleiomyomatosis (LAM), a rare cystic lung disease that occurs primarily in women, has had considerable success. ${ }^{11}$ The cohort of identified individuals with LAM has been used to characterise the clinical features of subjects and has provided information on the natural course of the disease. The registry includes clinical data and tissue samples that are used to study the pathophysiology of the condition and assess interventions. Data and tissue samples are also banked for future studies. Already this registry has yielded new information that is changing our view of this disease. ${ }^{11}$

Another important example of the effectiveness of a coordinated registry-based approach has been in cystic fibrosis in both North America ${ }^{12}$ and Europe. ${ }^{13}$ Database analysis has provided information in relation to pharmacoepidemological research, ${ }^{13}{ }^{14}$ socioeconomic determinates ${ }^{15}$ the effect of genetic factors, ${ }^{16}$ timing for referral for lung transplantation, ${ }^{17}$ determinates of mortality ${ }_{1}^{18}$ quality assurance for comparative purposes ${ }^{19}$ and the development of survival models of disease. ${ }^{20}$ Because of the often centre-specific nature of disease management, participating centres in the North American database found that a uniformity of approach and reporting methods substantially improved outcome analysis. The European database for cystic fibrosis (ESCF) has produced significant results in relation to the use of novel therapies. ${ }^{14}$ To date, advances in data collection have generally been the result of compilation through tertiary referral centres. Biases in reporting are likely to arise through reporting from larger more active centres, particularly if associated with the use of lung transplantation as a therapeutic option. 


\section{STATUS OF CURRENT INTERSTITIAL LUNG DISEASE REGISTRIES}

None of the current registries has focused specifically on IPF. Most have attempted to study epidemiological data on the prevalence, incidence or relative frequency of the different interstitial lung diseases. A review of interstitial lung disease registries from three countries in Europe (Belgium, ${ }^{21}$ Germany ${ }^{22}$ and Italy $^{23}$ ) and from Bernalillo County, New Mexico in the USA showed some striking similarities, but also many discrepancies. ${ }^{24}$ Nonetheless, some significant issues have been addressed using local databases. The same message emerges from a survey of interstitial lung diseases published in the European Lung White Book. ${ }^{1}$ Data on registries from Flanders, Germany, Italy and Spain are presented in this review, which points out that current registry data suffer from bias due to incomplete registration that precludes establishing true incidence and prevalence. Variability in diagnostic criteria further hampers interpretation of these data; this may account for the differences observed in IPF incidence (lower in Flanders), sarcoidosis (lower in Spain) and hypersensitivity pneumonitis (lower in Italy and Spain), but could also be flagging up real differences that are worthy of further study. Such variability, if confirmed, may provide important clues about causation, especially environmental factors.

Surprisingly large differences in the use of diagnostic techniques-such as high-resolution CT scanning, bronchoalveolar lavage, open lung biopsy and transbronchial lung biopsy-have been observed in different studies. ${ }^{124}$ Coultas and co-workers in New Mexico examined the relationship between the confirmed diagnosis of IPF and accuracy of death certificates, concluding that IPF was very often under-recognised and inaccurately coded at the time of death. ${ }^{25}{ }^{26}$ Studies of interstitial lung diseases from Italy identified a surgical biopsy rate of $20 \%$ and chest imaging rate of $74 \% .{ }^{23}$ A Spanish study found a biopsy rate of $22 \%$ and CT chest imaging rate of $93 \%,{ }^{27}$ and in Finland the biopsy rate was 31\% while chest imaging was used in $90 \%$ of diagnoses. ${ }^{28}$ An analysis of German data found that bronchoalveolar lavage and tissue sampling were extensively used to confirm the diagnosis of IPF, while imaging studies were relatively underused. ${ }^{22}$

\section{MAJOR GOALS OF AN INTERNATIONAL IPF REGISTRY}

The purpose of the IPF registry will be to develop an international database of persons with IPF. Experience with analysis of multicentre data has emphasised the need for uniformity in approach, adequate verification of data accuracy and inclusion of quality indices and audit to estimate underreporting. ${ }^{13}$ Comparisons across databases can be achieved, identifying factors of importance to healthcare systems, especially health economic issues. ${ }^{29}$ The ascertainment of a minimum dataset and facilitated entry, made possible by the internet, now makes global collaboration a reality.

The IPF Registry will be used to:

- Provide a minimum estimate of the prevalence and incidence of IPF.

- Provide a comprehensive clinical picture of IPF.

- Establish optimal investigation strategies.

- Track the functional abilities, access to health care and cost of caring for those with IPF over time.

- Encourage collaborative research between institutions and provide a resource for clinical and laboratory research. This registry could be the coordinating core for the conduct of coordinated laboratory and clinical research and clinical trials of therapy in IPF. It could facilitate the conduct of investigations into the aetiology, pathogenesis and treatment of IPF through standardised collection and coordinated use of medical and exposure history, clinical data, blood, urine and tissue samples, and DNA.

- Drive the development of innovative research projects and facilitate the development of new therapies and healthcare services to improve the quality of life for people with IPF.

- Accelerate the process of informing patients of research projects for which they may be eligible.

- Improve assess to current treatment approaches and assist in the development of best practice guidelines.

- Develop a bioinformatics platform that links molecular data to clinical data. This platform would include a user-friendly mechanism for depositing data and readily available portals of access to obtain and use the data. ${ }^{30}$

- Establish a mechanism for systematic phenotype and genotype characterisation of patients and family members in association with a standardised collection of medical and environmental exposure histories for use in gene/environment investigations of the aetiology. ${ }^{30}$

Competing interests: None.

\section{REFERENCES}

1. Anon. Interstitial lung diseases. In: Loddenkemper R, Gibson GJ, Sibille Y, eds. European Lung White Book. Lausanne: European Respiratory Society, 2003:74-83.

2. American Thoracic Society. Idiopathic pulmonary fibrosis: diagnosis and treatment. International consensus statement. American Thoracic Society (ATS) and the European Respiratory Society (ERS). Am J Respir Crit Care Med 2000;161(2 Pt 1):646-64.

3. American Thoracic Society/European Respiratory Society. International Multidisciplinary Consensus Classification of the Idiopathic Interstitial Pneumonias. Joint statement of the American Thoracic Society (ATS) and the European Respiratory Society (ERS) adopted by the ATS board of directors, June 2001 and by the ERS Executive Committee, June 2001. Am J Respir Crit Care Med 2002;165:277-304.

4. Mukerjee D, St George D, Coleiro B, et al. Prevalence and outcome in systemic sclerosis associated pulmonary arterial hypertension: application of a registry approach. Ann Rheum Dis 2003;62:1088-93.

5. Whelan TP, Dunitz JM, Kelly RF, et al. Effect of preoperative pulmonary artery pressure on early survival after lung transplantation for idiopathic pulmonary fibrosis $J$ Heart Lung Transplant 2005;24:1269-74.

6. Keck BM, Bennett LE, Fiol BS, et al. Worldwide thoracic organ transplantation: a report from the UNOS/ISHLT International Registry for Thoracic Organ Transplantation. Clin Transpl 1995:35-48.

7. Bennett LE, Keck BM, Hertz Ml, et al. Worldwide thoracic organ transplantation: a report from the UNOS/ISHLT international registry for thoracic organ transplantation. Clin Transp/ 2001:25-40.

8. Christie JD, Carby M, Bag R, et al. Report of the ISHLT Working Group on Primary Lung Graft Dysfunction part II: definition. A consensus statement of the International Society for Heart and Lung Transplantation. J Heart Lung Transplant 2005;24:1454-9.

9. Hosenpud JD, Bennett LE, Keck BM, et al. Effect of diagnosis on survival benefit of lung transplantation for end-stage lung disease. Lancet 1998;351:24-7.

10. Shorr AF, Davies DB, Nathan SD. Outcomes for patients with sarcoidosis awaiting lung transplantation. Chest 2002;122:233-8.

11. Ryu JH, Moss J, Beck GJ, et al. The NHLBI Lymphangioleiomyomatosis Registry: characteristics of 230 patients at enrollment. Am J Respir Crit Care Med 2006;173:105-11.

12. Rosenfeld M. Overview of published evidence on outcomes with early diagnosis from large US observational studies. J Pediatr 2005;147(3 Suppl):S11-4.

13. Strobl J, Enzer I, Bagust A, et al. Using disease registries for pharmacoepidemiological research: a case study of data from a cystic fibrosis registry. Pharmacoepidemiol Drug Saf 2003;12:467-73.

14. Hodson ME, McKenzie S, Harms HK, et al. Dornase alfa in the treatment of cystic fibrosis in Europe: a report from the Epidemiologic Registry of Cystic Fibrosis. Pediatr Pulmonol 2003;36:427-32.

15. O'Connor GT, Quinton HB, Kneeland T, et al. Median household income and mortality rate in cystic fibrosis. Pediatrics 2003;111(4 Pt 1):e333-9.

16. McKone EF, Emerson SS, Edwards KL, et al. Effect of genotype on phenotype and mortality in cystic fibrosis: a retrospective cohort study. Lancet 2003;361:1671-6.

17. Mayer-Hamblett N, Rosenfeld M, Emerson J, et al. Developing cystic fibrosis lung transplant referral criteria using predictors of 2-year mortality. Am J Respir Crit Care Med 2002;166:1550-5 
18. Emerson J, Rosenfeld M, McNamara S, et al. Pseudomonas aeruginosa and other predictors of mortality and morbidity in young children with cystic fibrosis. Pediatr Pulmonol 2002;34:91-100

19. Wiedemann B, Steinkamp G, Sens B, et al. The German cystic fibrosis quality assurance project: clinical features in children and adults. Eur Respir J 2001;17:1187-94.

20. Liou TG, Adler FR, Fitzsimmons SC, et al. Predictive 5-year survivorship model of cystic fibrosis. Am J Epidemiol 2001:153:345-52.

21. Roelandt M, Demedts $\mathbf{M}$, Callebaut W, et al. Epidemiology of interstitial lung disease (ILD) in Flanders: registration by pneumologists in 1992-1994. Working group on ILD, VRGT. Vereniging voor Respiratoire Gezondheidszorg en Tuberculosebestrijding. Acta Clin Belg 1995; 50:260-8.

22. Schweisfurth H, Kieslich C, Satake N, et al. [How are interstitial lung diseases diagnosed in Germany? Results of the scientific registry for the exploration of interstitial lung diseases ("Fibrosis registry") of the WATL]. Pneumologie 2003:57:373-82.

23. Agostini C, Albera C, Bariffi F, et al. First report of the Italian register for diffuse infiltrative lung disorders (RIPID). Monaldi Arch Chest Dis 2001;56:364-8.
24. Thomeer MJ, Costabel U, Rizzato G, et al. Comparison of registries of interstitial lung diseases in three European countries. Eur Respir J 2001;18(32 Suppl):114-8S

25. Coultas DB, Zumwalt RE, Black WC, et al. The epidemiology of interstitial lung diseases. Am J Respir Crit Care Med 1994:150:967-72.

26. Coultas DB, Hughes MP. Accuracy of mortality data for interstitial lung diseases in New Mexico, USA. Thorax 1996;51:717-20.

27. Xaubet A, Ancochea J, Morell F, et al. Report on the incidence of interstitial lung diseases in Spain. Sarcoidosis Vasc Diffuse Lung Dis 2004;21:64-70.

28. Hodgson U, Laitinen T, Tukiainen P. Nationwide prevalence of sporadic and familial idiopathic pulmonary fibrosis: evidence of founder effect among multiplex families in Finland. Thorax 2002;57:338-42.

29. McCormick J, Sims EJ, Green MW, et al. Comparative analysis of Cystic Fibrosis Registry data from the UK with USA, France and Australasia. J Cyst Fibros 2005;4:115-22.

30. Crystal RG, Bitterman PB, Mossman B, et al. Future research directions in idiopathic pulmonary fibrosis. Summary of a National Heart, Lung, and Blood Institute Working Group. Am J Respir Crit Care Med 2002;166:236-46.

\section{Lung alert}

\section{Simple control measures could substantially reduce predicted spread of XDR TB}

Extensively drug resistant tuberculosis (XDR TB) is TB with resistance to isoniazid, rifampicin, any fluoroquinolone, and at least one of the three injectable sideline drugs. Cases have been reported in 37 countries worldwide since March 2006, with South Africa having the largest cluster of patients. Nosocomial transmission of XDR has been suggested as the driver of this epidemic, typically in HIV-infected patients, and this study looks at various control measures and the effect they could have on transmission rates by the end of 2012 .

Airborne TB transmission was simulated using a mathematical model based on current spread in a rural region of South Africa (Tugela Ferry) served by a typical hospital. The effectiveness of interventions was also predicted using this model.

The model predicted that XDR cases would increase from 194/year in 2007 to 234/year in 2012 if no new interventions are implemented; 72-96\% of these cases would occur in patients with HIV infection. The proportions of TB patients with multidrug resistant (MDR) and $\mathrm{XDR} T \mathrm{~TB}$ would increase to $78 \%$ and $48 \%$, respectively.

Preventive measures such as shorter hospital admissions, rapid dug susceptibility assays, isolation facilities, respiratory mask use and improvements in ventilation all prevented XDR cases individually, and had even greater preventive value when used in combination, preventing $48 \%$ of future XDR cases in total.

Although the authors' conclusions are based on model assumptions, the study provides a compelling incentive to implement simple nosocomial infection control measures in populations which are resource-constrained and already experiencing an HIV epidemic to effectively control a possibly disastrous epidemic of XDR TB.

- Basu S, Andrews JR, Poolman EM, et al. Prevention of nosocomial transmission of extensively drug-resistant tuberculosis in rural South African district hospitals: an epidemiological modelling study. Lancet 2007;370:1500-7

\section{Shazia Khan}

Correspondence to: S Khan, Respiratory/TU SHO, London, UK; shaziakhan@doctors.org.uk 